\title{
Duodenal Xanthoma: From Specks to Obstruction
}

\author{
Sindhura Kolli ${ }^{1}$, Dan C. Phan ${ }^{2}$, Mel A. Ona ${ }^{3}$ \\ 1. Internal Medicine, The Brooklyn Hospital Center, New York, USA 2. Pathology, Convenant Pathology Services, San \\ Francisco, USA 3. Gastroenterology, Pali Momi Medical Center, Honolulu, USA
}

Corresponding author: Sindhura Kolli, sindhura.kolli@gmail.com

\begin{abstract}
Xanthomas within the gastrointestinal tract occur secondary to a mucosal insult. When enough cells accumulate, their appearance can range from small nodules studding the intestinal mucosa to bandlike infiltrations to pseudotumor-like masses within the intestine with fibrosis and inflammation resembling malignancy. When large enough, they can produce symptoms of obstruction such as vomiting, abdominal pain, distention, and dysmotility. This case demonstrates the epidemiology, clinical presentation, diagnosis, and treatment of duodenal xanthomas.
\end{abstract}

Categories: Internal Medicine, Medical Education, Gastroenterology Keywords: duodenal xanthoma, xanthoma, foamy macrophages

\section{Introduction}

Xanthomas are commonly limited to the skin and rarely occur within the gastrointestinal tract. They are caused by an exaggerated response to a past mucosal insult, the lipid laden debris consumed by histiocytes that persist as foamy macrophages. Duodenal xanthomas have a wide spectrum of presentation from whitish speckling of mucosa to larger masses within the small intestine causing obstruction [1-2]. This case demonstrates its epidemiology, clinical presentation, diagnosis, and treatment.

\section{Case Presentation}

A 75-year-old Japanese female with gastroesophageal reflux disease (GERD), dyslipidemia, hypothyroidism, and osteoporosis, presented with a two-month history of intermittent dysphagia to solid food associated with bloating and unintentional weight loss of seven pounds over two months. The dysphagia was aggravated with the consumption of starchy foods and alleviated with drinking water.

Esophagram findings demonstrated mild to moderate nonspecific esophageal dysmotility. An esophagoduodenoscopy (EGD) demonstrated gastric erythema and erosions with areas of desquamation in the antrum and prepyloric region (Figures 1-2).

Received 04/29/2019

Review began 05/05/2019 Review ended 05/06/2019 Published 05/14/2019

๑) Copyright 2019

Kolli et al. This is an open access article distributed under the terms of the Creative Commons Attribution License CC-BY 3.0., which permits unrestricted use, distribution, and reproduction in any medium, provided the original author and source are credited.

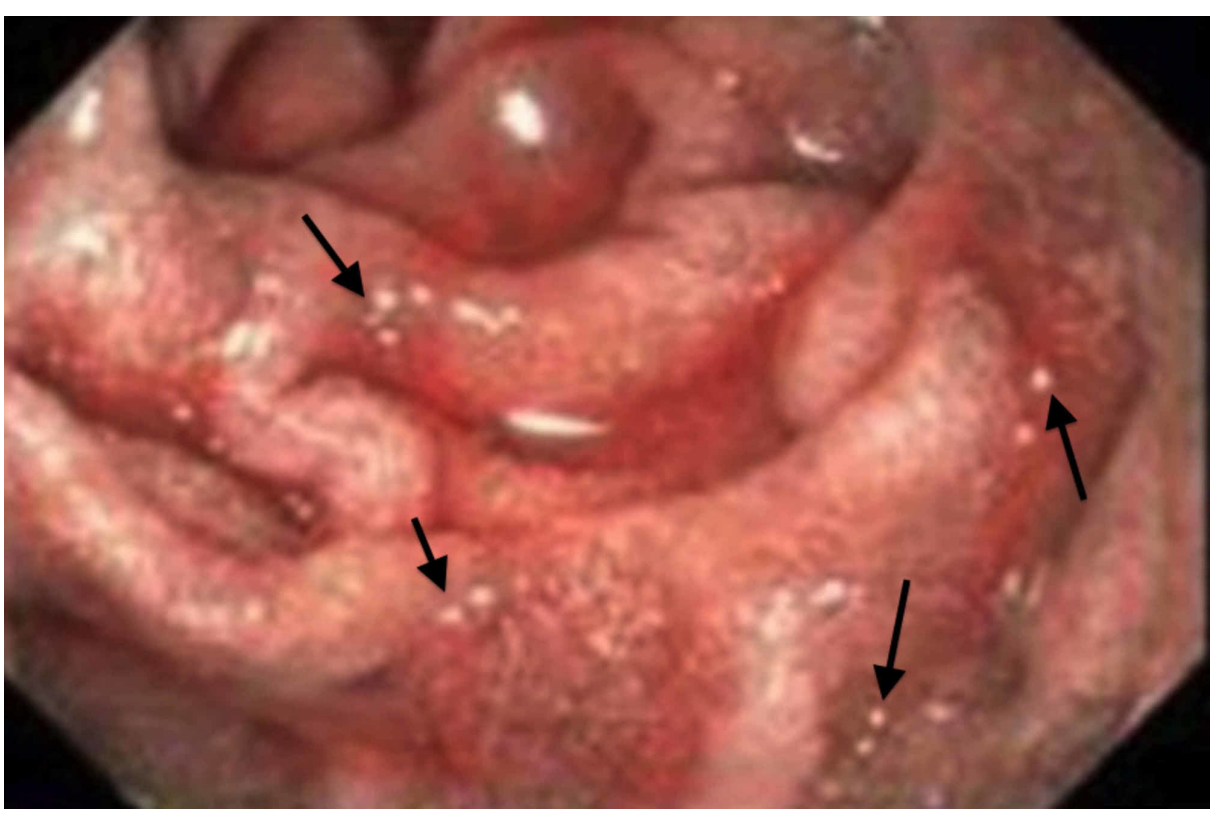

FIGURE 1: Duodenal xanthoma seen as white speckling of mucosa 


\section{Cureus}

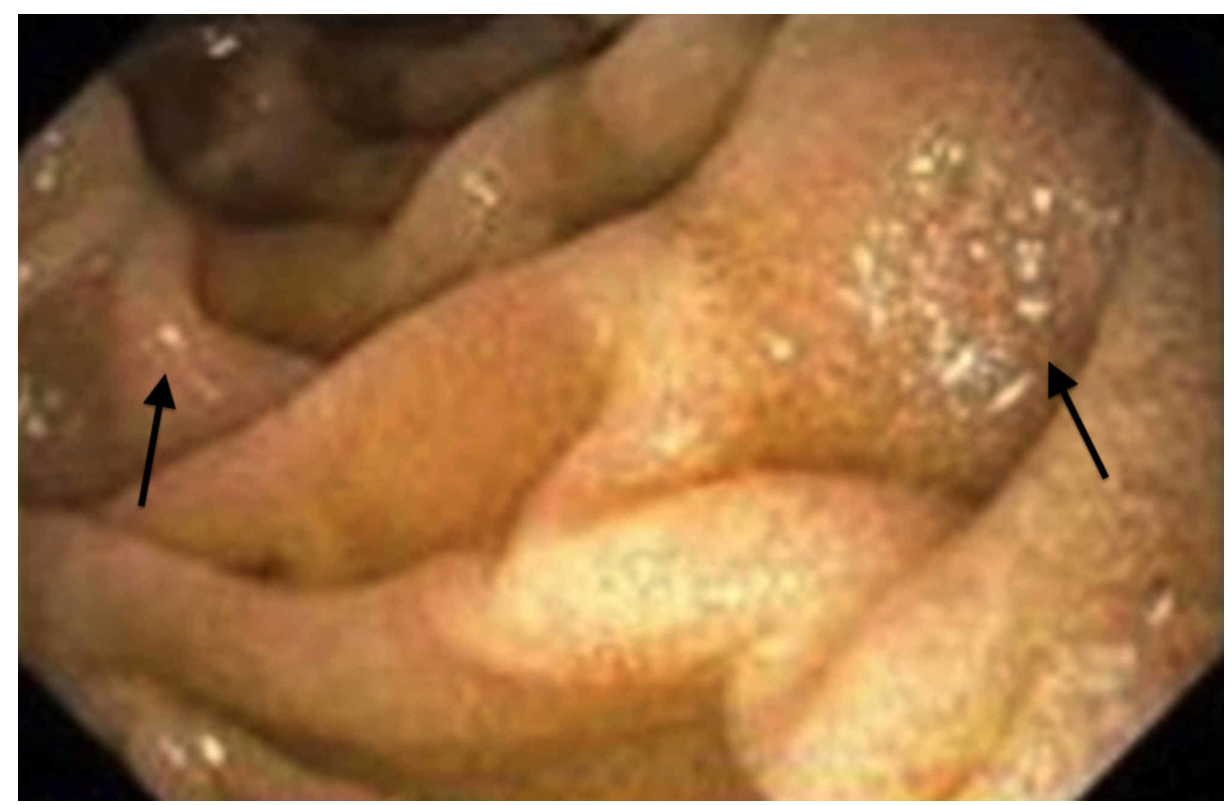

FIGURE 2: Narrow band imaging of duodenal xanthoma seen as white specks

Biopsies were taken from the bulb and second portion of the duodenum which were positive for duodenal xanthoma. The patient was recommended for a repeat procedure for further resection of the xanthoma only if the dysphagia persisted. However, it resolved and the patient was recommended the procedure if the symptoms returned.

\section{Discussion}

In terms of intestinal obstruction, duodenal xanthomas are on the far end of the spectrum of differentials. Xanthomas are considered to be an exaggerated response to a past mucosal insult, the lipid-laden debris consumed by histiocytes that persist as foamy macrophages. With a predilection for skin, they are rarely seen in the gastrointestinal tract. They tend to occur more commonly in the stomach and then in the esophagus (based on literature) with the duodenum as a distant third [1-2]. When enough cells accumulate, their appearance can range from small nodules studding the intestinal mucosa to bandlike infiltrations to pseudotumor-like masses within the intestine with fibrosis and inflammation resembling malignancy. When large enough, they can produce symptoms of obstruction such as vomiting, abdominal pain, distention, and dysmotility [1]. The limited number of cases show a penchant for males $6: 1$ to females and have a tenuous association with dyslipidemias, chemotherapy, radiation, and cytomegalovirus (CMV) colitis; however, larger studies are needed to determine the significance of these causal relationships [2].

Diagnosis is made by endoscopy and biopsy with immunohistochemistry (IHC) staining confirming foamy histiocytes distributed through three layers (serosa, muscularis propria, and submucosa), positive for cluster of differentiation 68 (CD68), decreased smooth muscle, and occasionally accompanied by fibrosis (Figure 3). 


\section{Cureus}

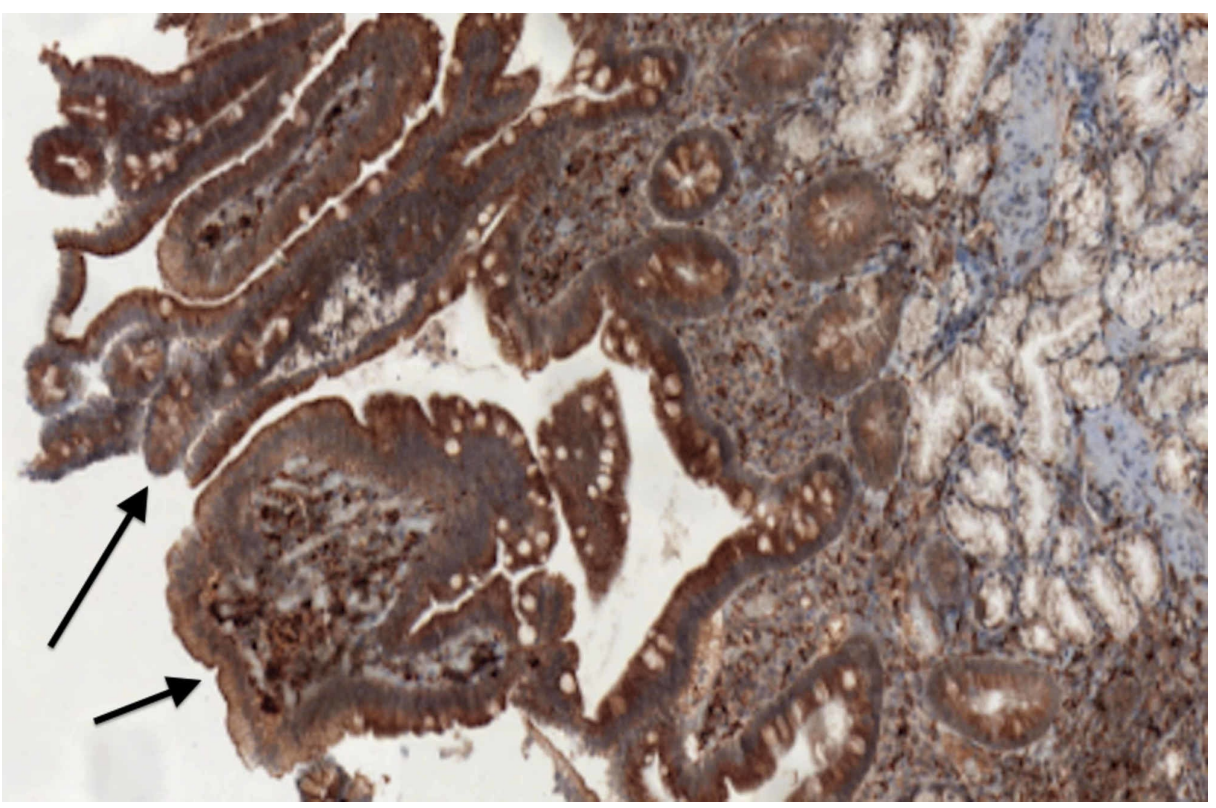

FIGURE 3: Cluster of differentiation 68 (CD68) positive macrophages on immunohistochemistry (IHC)

Electron microscopy demonstrated foam cells with fatty cytoplasm, as seen in Figure 4 [1-2]. Treatment involves endoscopic mucosal resection and for larger lesions, duodenal preserving surgery [3].

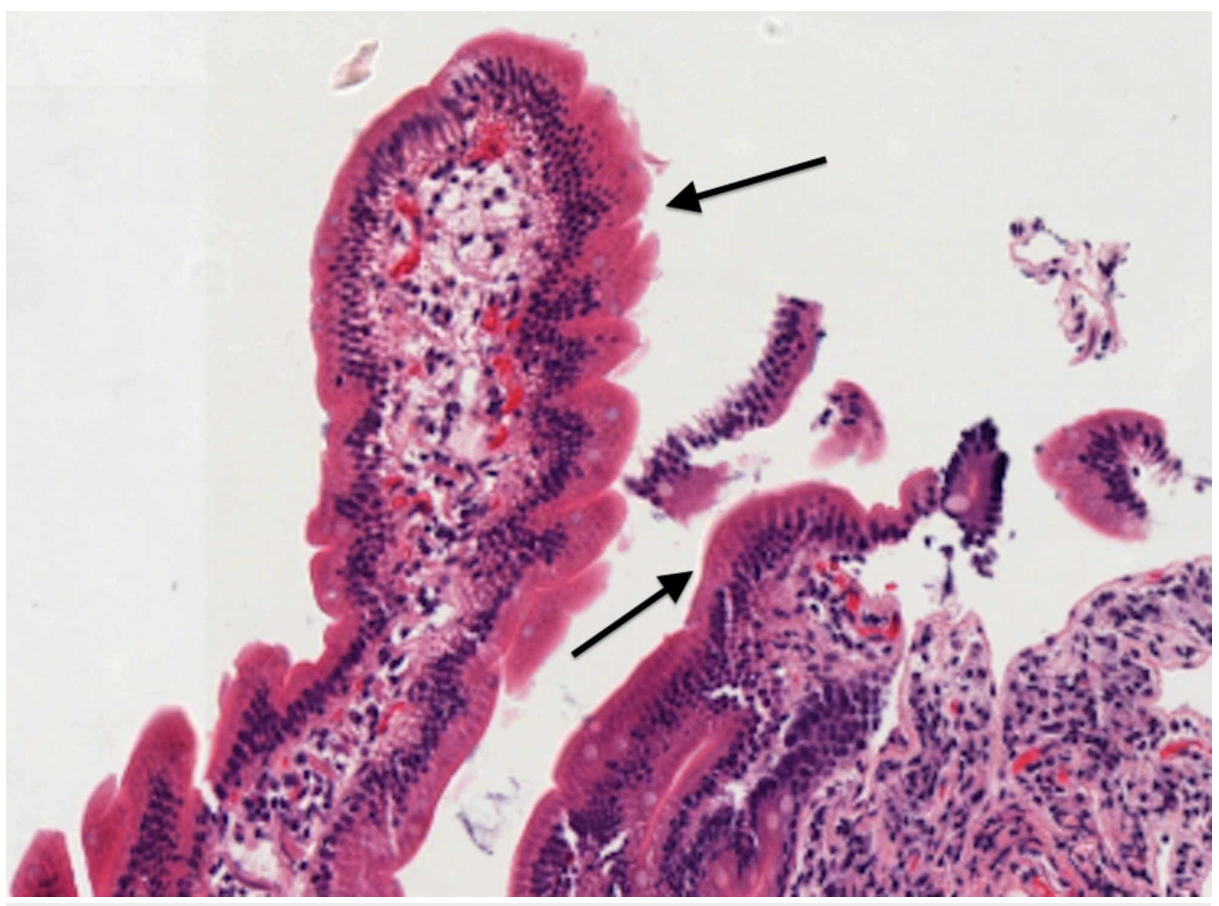

FIGURE 4: Electron microscopy of foamy macrophages of duodenal xanthoma

\section{Conclusions}

Despite being an uncommon differential in intestinal obstruction, Xanthomas should be considered when patients with insults from chemotherapy, radiation, or/and CMV colitis present. Xanthomas range in presentation and size, sometimes requiring surveillance, but may also require intestine-preserving surgery. Due to this rare occurrence and wide range of presentation, duodenal xanthomas are not a dismissive matter, rather they require endoscopists' attention. 


\section{Additional Information}

Disclosures

Human subjects: Consent was obtained by all participants in this study. Brooklyn Hospital Center IRB Board issued approval n/a. Thank you for submitting the Publication materials for this project. The Brooklyn Hospital Center IRB has APPROVED your submission. No further action on this submission is required at this time. The following items are acknowledged in this submission: • Abstract/Summary-IRBDuodenal Xanthoma • ApplicationForm-CaseReportApplication • ConsentForm-CaseReportConsent If you have any questions, please contact Twyla Tate at 718-250-6947 or ttate@tbh.org. Please include your project title in all correspondence with this committee. . Conflicts of interest: In compliance with the ICMJE uniform disclosure form, all authors declare the following: Payment/services info: All authors have declared that no financial support was received from any organization for the submitted work. Financial relationships: All authors have declared that they have no financial relationships at present or within the previous three years with any organizations that might have an interest in the submitted work. Other relationships: All authors have declared that there are no other relationships or activities that could appear to have influenced the submitted work.

\section{References}

1. Barrera-Herrera LE, Arias F, Rodríguez-Urrego PA, Palau-Lázaro MA: Small bowel obstruction due to intestinal xanthomatosis. Case Rep Pathol. 2015, 1-4. Accessed: March 12, 2019 : https://www.hindawi.com/journals/cripa/2015/231830/. 10.1155/2015/231830

2. Delacruz V, Takahashi H, Nishida S, Tzakis A, Ruiz P: Segmental xanthomatosis of the small intestine. A case report and review of the literature. Hum Pathol. 2009, 40:139-142. 10.1016/j.humpath.2008.05.016

3. Dhakal M, Dhakal OP, Bhandari D, Gupta A: Gastric xanthelasma: an unusual endoscopic finding. BMJ Case Rep. 2013, 2013:Accessed: March 18, 2019: https://casereports.bmj.com/content/2013/bcr-2013-201017. 10.1136/bcr-2013-201017 